\title{
Deus deceptor. En torno a los conceptos de potencia, trascendencia y racionalidad en la metafísica de Descartes
}

\section{Deus deceptor. On the concepts of Power, Transcendence and Rationality in Descartes' Metaphysics}

\author{
Pedro Lomba FAlCóN \\ (Universidad Complutense de Madrid)
}

Recibido: 18/04/2011

Aceptado: 15/11/2011

\section{Resumen}

En el presente artículo se ensaya la determinación del momento realmente innovador de la metafísica de Descartes, esto es, de la conceptualización sobre la que van a girar las polémicas filosóficas más significativas en la posterioridad inmediata a la construcción de su sistema. Dicho momento estará, más que en el descubrimiento del cogito y sus implicaciones para la reforma del saber, en la manera como el francés reconceptualiza la noción de potencia divina, pues a partir de ella forjará los conceptos de trascendencia y racionalidad, tan pregnantes en su obra y a lo largo del siglo XVII.

Palabras clave: Potencia, trascendencia, racionalidad, inteligibilidad, creación, primera modernidad.

\begin{abstract}
In this article, I try to determine the innovatory moment of Descartes' Metaphysics, that is, the conceptual work that became the turning point in the most significant philosophical polemics in the subsequent period after the construction of Cartesian system. This turning point is the way Descartes thinks the concept of divine power, rather than the discovery of the cogito or its implications in re-shap-
\end{abstract}


ing knowledge. Starting from this, Descartes will forge the concepts of transcendence and rationality, so essential in his works and all along the second half of XVIIth century.

Keywords: Power, Transcendence, Rationality, Intelligibility, Creation, Modernity.

Pocas cuestiones gozan de mayor consenso en filosofía que la de la función histórica desempeñada por la metafísica de Descartes: con ella se habría inaugurado una época del pensamiento radicalmente nueva - moderna-, de modo que la forma de todo el saber previo habría sido liquidada definitivamente, quedando confinado éste en un pasado ya del todo irrecuperable. La idea fue fijada en nuestra cultura por Hegel, quien en sus Lecciones sobre la historia de la filosofía reconoce en la obra del francés un verdadero momento inicial, un punto de partida casi absoluto. ${ }^{1}$ Por ello, cuando desde la historiografía filosófica contemporánea se afirma que el sistema cartesiano determina la irrupción de una forma nueva del pensar, se significa que con él adquiere su fisonomía propia un espacio teórico muy preciso; es decir, una serie de tópicos a los cuales deberá atenerse, de una manera u otra, toda reflexión posterior a la suya: el cogito, la duda, la verdad y el método, la libertad de la voluntad, la existencia de Dios y sus pruebas, etc. Pero se afirma sobre todo, más fundamentalmente, que con su metafísica se despliega una lógica en función de la cual son ordenados y tratados dichos tópicos -tomados en realidad de ciertas tradiciones preexistentes $^{2}$; lo novedoso sería el orden en que nuestro autor los dispone y el uso que hace de ellos, claramente orientado a unos fines muy concretos, ajenos a los que determinaban el sentido de esas tradiciones- que ya no podrá dejar de ser transitada por quienes tengan algo relevante que decir en filosofía durante el siglo XVII. ${ }^{3}$ De esta lógica, por tanto, es de lo que deberán apropiarse necesariamente quienes pretendan construir un sistema filosófico sólido en la primera modernidad, bien sea para desarrollarla o discutirla en alguno de sus puntos esenciales, bien sea para abandonarla tajantemente por ser considerada deficiente o incluso perfectamente desechable. Con el presente trabajo quisiéramos intervenir en esta cuestión del vuelco teórico acometido por la metafísica de Descartes para intentar precisar con algún rigor sus límites y su sentido.

${ }^{1}$ Cf. G.W.F. Hegel, Lecciones sobre la historia de la filosofia (trad. española de W. Roces), 3 vols., México, FCE, vol. 3, p. 252.

$2 \mathrm{Al}$ estudio de esta cuestión ha consagrado sus esfuerzos, entre otros, Étienne Gilson. Cf., por ejemplo, su Index scolastico-cartésien, Nueva York, Burt Franklin, s.f. (París, 1912), o sus Études sur le rôle de la pensée médiévale dans la formation du système cartésien, París, Vrin, 1967 (1930).

3 Cf. Jean-Luc Marion, Sur la théologie blanche de Descartes. Analogie, création des vérités éternelles et fondement, París, P.U.F., 1991 (1981), pp. 11 y ss. 
Si aceptamos el carácter inaugural de la obra cartesiana, quizás sea preciso afirmar que la característica última que define en su especificidad a esa «nueva filosofía» que con ella toma forma ha sido la refundación de la estructura del saber partiendo de una consideración muy determinada de los «principios del conocimiento». Descartes, en efecto, propone un orden totalmente inaudito según el cual se deben organizar las partes de la filosofía; orden éste que va a definir la función que cada uno de aquellos tópicos cumple en su propio sistema. Es por ello por lo que tal vez pueda afirmarse legítimamente -él mismo percibe su trabajo de este modo en muchos pasajes estratégicos de sus escritos 4 - que la revolución teórica 5 de la que normalmente se le hace responsable consiste en el diseño de una nueva estructuración lógica y metodológica de las «regiones» de que se ha hecho constar tradicionalmente a la metafísica, siendo aquel orden antiguo desechado con gesto firme un orden que quedaba garantizado por la distinción entre una metaphysica generalis y una metaphysica specialis que, a su vez, se dividía en tres momentos fundamentales.

La prueba está en un texto justamente célebre, y celebrado. Leemos en la carta al abate Claude Picot que sirve como prefacio a la traducción francesa de los Principia philosophiae una explicación emblemática a propósito de las partes de que debe constar esa «verdadera filosofía» cuya pretensión es la de no tener absolutamente nada que ver con lo que hasta el momento se ha hecho en el terreno del «saber»:

[...] la primera parte es la metafísica, que contiene los principios del conocimiento, entre los cuales está la explicación de los principales atributos de Dios, de la inmaterialidad de nuestras almas, y de todas las nociones claras y simples que están en nosotros 6

La lección del texto es cristalina: la primera parte que debe organizar el sistema de la filosofía es la metafísica, cuyo contenido queda cifrado ahora en ciertos «principios del conocimiento», los cuales, a su vez, constituyen el punto de partida desde el cual deben abordarse y ser elaborados todos los temas de la «nueva filosofía», al menos bajo la forma que ésta adquiere con la reflexión cartesiana. Y será el pensa-

\footnotetext{
${ }^{4}$ Los textos son prácticamente innumerables. Cf. a modo de ejemplo Las pasiones del alma, I, art. 1 (AT, XI, 327-328), el prefacio de la traducción francesa de los Principios de filosofía (AT, IX-2, 1-20), la carta al padre Dinet sobre las séptimas Objeciones a las Meditaciones metafísicas (AT, VII, 563603), etc. Citaremos las obras de Descartes según la edición de Charles Adam y Paul Tannery (Eeuvres de Descartes, París, Vrin, 1996 (1897-1913), 11 vols.) siguiendo el uso tradicional de consignar la abreviatura AT seguida del número de volumen en romanos y de la página en arábigos. Todas las traducciones son nuestras.

5 Sobre el sentido «revolucionario» del nuevo saber científico y filosófico «moderno», cf. PierreFrançois Moreau, Hobbes. Philosophie, science, religion, París, P.U.F., 1989, pp. 18-52.

${ }^{6}$ Les Principes de la Philosophie (AT, IX-2, 14).
} 
miento y su irrefutable existencia lo que pasará a arrogarse el papel de primer principio entre los principios de la metafísica: 7

[...] he tomado el ser o la existencia de este pensamiento por el primer principio, del cual he deducido muy claramente los siguientes, a saber, que hay un Dios que es autor de todo lo que es en el mundo, y que, puesto que es la fuente de toda verdad, no ha creado nuestro entendimiento de tal naturaleza que pueda engañarse en el juicio que hace acerca de las cosas de las que tiene una percepción muy clara y muy distinta ${ }^{8}$

El pensamiento - el cogito- se postula como primer principio, precisamente, porque la verdad de su existencia va a mostrarse como inatacable; esto es, porque partiendo de sus contenidos y de su propio estatuto podrá ser deducido «muy claramente» todo lo que dará cuerpo a la «verdadera» filosofía: «la explicación de los principales atributos de Dios, de la inmaterialidad de nuestras almas, y de todas las nociones claras y simples que están en nosotros», como se dice en el prefacio citado y no deja de repetirse en prácticamente todas las obras de madurez del francés. Con su obra, por tanto, parece quedar inaugurada la época de la perfecta conjunción entre la subjetividad $-\mathrm{O}$, por mejor decir, la estructura racional de la conciencia- $\mathrm{y}$ el fundamento de la consistencia ontológica de todas las cosas. El vuelco teórico que define la nueva manera de hacer filosofía, así pues, parece consistir en primera instancia en una reorganización de las «partes» que tradicionalmente se ha venido atribuyendo a la metafísica. Y dicha reorganización indica que la filosofía debe identificar el «primer principio» con el «fundamento» -o punto de partida- de la reflexión abandonando así la forma previa del saber, en la cual se identificaba, por un lado, «primer principio»y, por otro, «fundamento» o «causa» del ser. La revolución teórica que nos ocupa se resuelve de esta manera, necesariamente, en la introducción de un cierto desajuste expositivo entre ordo essendi y ordo cognoscen$d i$. La filosofía no puede ya comenzar, sin más -afirma nuestro autor explícita o implícitamente, una y otra vez-, por la idea de Dios.

En efecto, si nos remontamos un poco en el tiempo, podemos constatar que la elaboración de aquella conjunción o simbiosis había quedado fijada de manera programática en el Discurso del método, uno de sus primeros textos propiamente filosóficos. Leemos en su sexta parte:

En primer lugar, he tratado de encontrar en general los principios, o primeras causas, de todo lo que es, o puede ser, en el mundo, sin considerar ninguna otra cosa, a este efec-

\footnotetext{
7 Ya desde el Discurso del método, es decir, desde 1637: «Y al observar que esta verdad: yo pienso, luego existo, era tan firme y tan segura que ninguna de todas las suposiciones más extravagantes de los escépticos era capaz de socavarla, juzgué que la podía aceptar, sin escrúpulo alguno, como primer principio de la filosofía que buscaba» (AT, VI, 32).
}

8 AT, IX-2, 10. 
to, que a Dios, que lo ha creado, ni extraerlos de ningún otro sitio que de ciertas simientes de la verdad que se hallan naturalmente en nuestras almas. Tras esto, he examinado cuáles eran los primeros y más comunes efectos que se pueden deducir de estas causas 9

Lo que hace que este pasaje sea interesante para nuestros propósitos es que en esa refundación de la filosofía, tal como aquí se anuncia, se puede localizar aquella suerte de desajuste o de paradoja a la que acabamos de hacer alusión: a pesar de que se afirma en él que se ha de considerar simultáneamente a Dios para encontrar los primeros principios o primeras causas de todo, se afirma también, con no menos claridad, una ineludible separación o distancia estructural entre la sola consideración de Dios y la sola utilización de «ciertas simientes de la verdad». Dichos principios o primeras causas sólo pueden ser «extraídos» de ciertas ideas natural o ingénitamente contenidas en nuestra alma. Ciertas ideas o máximas -ciertos «principios del conocimiento»-son lo que nos descubre los principios o primeras causas de la realidad, a pesar de que la causa - el «autor»-de «todo lo que es en el mundo» no pueda ser una idea o una máxima. La coincidencia de ordo cognoscendi y ordo essendi, definitivamente, no parece ir de suyo. Para obtener y fundamentar tal ajuste o coincidencia se hace preciso un largo rodeo; la revolución teórica cartesiana quedará cifrada primeramente en la indicación de dicho desajuste $y$, en seguida, en el itinerario un tanto sorprendente 10 que deberá recorrerse para tratar de solucionarlo.

Digámoslo de otra manera: el principio o causa primera en el orden del ser de las cosas, incluso en el del ser de las verdades eternas es, como veremos a continuación,11 la voluntad absoluta y libre de Dios, la omnipotencia divina. Descartes considerará la omnipotencia de Dios como su principal atributo, al menos como el primer y principal atributo divino que el orden de las razones debe movilizar -aunque, debido quizás al momento designado como inicial, no tenga por qué

\footnotetext{
9 AT, VI, 63-64.

10 Sobre este asunto, es decir, sobre el llamado «círculo cartesiano», cf. la introducción de Vidal Peña García a su esencial edición y traducción de las Meditaciones metafísicas, Barcelona, Alfaguara, 1977, esp. pp. XXI-XLI.

11 Acerca de la teoría cartesiana de la creación de las verdades eternas, seguiremos, aparte de los estudios más generales que citamos en las correspondientes notas, los siguientes trabajos específicos: Émile Boutroux, De veritatibus aeternis apud Cartesium (tesis latina, París, 1874), traducción francesa de G. Canguilhem, Des vérités éternelles chez Descartes, París, Vrin, 1985 (1927); Geneviève Rodis-Lewis, Idées et vérités éternelles chez Descartes et ses successeurs, París, Vrin, 1985; Id., L'Euvre de Descartes, 2 vol., París, Vrin, 1971: I, cap. 3, § 5, pp. 125-140; Jean-Luc Marion, Sur la théologie blanche de Descartes. Analogie, création des vérités éternelles et fondement, op. cit.; $\mathrm{B}$. K. Rome, "Created truth and causa sui in Descartes», Philosophy and Phenomenological Research, 17 (1956), pp. 66-78; Jean-Marie Beyssade, La philosophie première de Descartes. Le temps et la cohérence de la métaphysique, París, Flammarion, 1979: cap. 2, pp. 101-128. En castellano, pueden consultarse las referencias a esta teoría en J. García López, El conocimiento de Dios en Descartes, Pamplona, EUNSA, 1976.
} 
hacerse visible desde el comienzo- para poner en marcha la reflexión sobre «todo lo que es o puede ser». Sin embargo, el primer principio o causa en el orden del conocimiento -el primer principio entre los «principios de la metafísica»- no será la idea de Dios, sino cierta verdad que se mostrará como inexpugnable. Por ello, en el resumen que cierra la primera parte de los Principios acerca de lo que podemos conocer a condición de seguir las prescripciones que impone la verdadera filosofía, aparece claramente un orden en el que la idea de Dios es evacuada del primer lugar que tal vez debería corresponderle por ser la causa primera o primer principio del ser de todas las cosas. 12 Descartes, por tanto, otorga la primacía en la construcción de la «verdadera filosofía» a una parte de lo que tradicionalmente ha sido llamado metaphysica specialis, para llegar, partiendo de ella, a la metafísica más general. 13

Pues bien, quizá esta reorganización de las partes de la metafísica sea posible tan sólo como reorganización en la que la prioridad de esa parte de la metaphysica specialis es únicamente expositiva, heurística. Se debe comenzar por el alma y su inatacable existencia, sí, pero este nuevo comienzo no puede dejar de venir determinado por una concepción muy precisa de Dios, de su potencia - «principio de todo lo que es»-, y, derivadamente, de la racionalidad misma. La tesis que aquí queremos someter a prueba es que una concepción de este tipo es lo que posibilita realmente esta reorganización del saber y da a éste tanto su sentido como su contenido material, efectivo, y también su orden. Es decir, es lo que genera el texto de la metafísica cartesiana, la selección de los tópicos que debe organizar y recorrer esa metafísica para constituirse tanto material como formalmente, y es también, sobre todo, lo que determina el orden y la manera como deben ser expuestos y pensados. Heurísticamente, Dios debe ser como reducido al rango de principio subordinado. Sin embargo, Dios no podrá ser considerado sino como principio subordinado tan sólo heurísticamente debido a que el primer momento de la reflexión no coincide o no se presenta de manera explícita como reflexión acerca del primer principio o primera causa de «todo lo que es o puede ser». Cuando Descartes se ocupe de demostrar la existencia de Dios, y cuando se ocupe de la problemática que envuelve el hecho de que el cogito sea finito y Dios infinito -cuando se ocupe de los temas que

\footnotetext{
12 Cf. AT, IX-2, 61: «[...] conoceremos, en primer lugar, que somos, en tanto que nuestra naturaleza consiste en pensar, y que hay un Dios del que dependemos; tras haber considerado sus atributos, podremos investigar la verdad de todas las demás cosas, pues Él es su causa». Lo que va a postularse como primer principio desde el cual construir todo el edificio filosófico no será determinada idea de Dios -causa primera-, sino el ser o la existencia del pensamiento, del cogito-verdad primera-. Es decir, el punto de partida estará en la captación de una verdad -cogito, sum-sólo a partir de la cual será posible construir la posibilidad de que las demás ideas, o determinado tipo de ellas, incluida la de Dios, sean verdaderas.

13 Es decir, toma la distinción clásica entre metafísica general y metafísica especial para darle la vuelta: los primeros principios están en lo que la tradición ha llamado metafísica especial. Pero esto es sólo un punto de partida. Cf. J.-L. Marion, Sur la théologie blanche de Descartes, op. cit., pp. 371-384.
} 
van a dar cuerpo a esta forma de la «nueva filosofía»-, las cosas serán puestas en su verdadero sitio ${ }^{14}$. Por ello, tal vez la radical novedad introducida por el sistema cartesiano, su auténtica fuerza conformadora de una nueva época del pensamiento, no esté exactamente donde la historiografía al uso la ha localizado.

En las páginas que siguen desarrollaremos esta hipótesis tratando de analizar el sentido último y las potencialidades de una tesis auténticamente fundamental y fundacional de este sistema: ni el cogito ni la verdad -la estructura racional de la realidad y de la conciencia, la racionalidad, primer principio en el orden del conocerpueden constituir el principio último, la instancia fundadora, de todo lo que es -el primer principio en el orden del ser-. Las verdades eternas -matemáticas, lógicas, físicas, morales; o sea, la estructura misma de esa conciencia de la que debe partir la reflexión si lo que pretende es encontrar un suelo rocoso sobre el que asentar sólidamente su curso- van a ser consideradas como libremente creadas por Dios. O lo que es lo mismo: la racionalidad, la necesidad racional y natural, es concebida necesariamente como algo creado. Dios, su omnipotencia, el principio, pues, que instaura tanto el ser como la racionalidad, será de modo absoluto, en consecuencia, un principio de suyo ininteligible. Esto es, absolutamente trascendente. Por ello, el fondo último del cartesianismo se revelará como un creacionismo o como un voluntarismo. Aunque como un voluntarismo ciertamente sui generis. Nuestra hipótesis, así pues, será la siguiente: quizás toda esta revolución teórica dependa directamente, más que de una reordenación de las partes de la metafísica, de una manera nueva de conceptualizar la potencia divina; reconceptualización orientada a poder vincular esa potencia de Dios - concepto vertebrador de determinadas tradiciones metafísicas propias de épocas previas, es decir, ya canceladas en virtud de la «nueva» forma del saber, supuestamente, de modo definitivo- a la cuestión considerada ahora por nuestro autor como decisiva, la de los «principios del conocimiento». Tal vez ese vuelco teórico consista, dicho de otra manera, en la tenaz y omnipresente reconceptualización de la naturaleza de Dios a que efectivamente se entrega, a que no puede dejar de entregarse desde el principio, desde el año 30, la escritura de Descartes.

En efecto, una cierta concepción de la voluntad de Dios en términos de libertad absoluta, o absolutamente indeterminada, parece ser realmente la condición que hace posible el giro acometido en relación con lo que puede constituir un punto de partida seguro para la «verdadera filosofía». La puesta en duda incluso de las «cosas de las que [el entendimiento] tiene una percepción muy clara y muy distinta» sólo tiene sentido si previamente es supuesta la posibilidad de que Dios haya creado el mundo, incluida nuestra conciencia o la racionalidad de su estructura, desde una cierta arbitrariedad, es decir, sin atenerse necesariamente a la racionalidad de que

14 Cf. ibid., p. 371. 
son muestra, por ejemplo, las verdades de las matemáticas y la geometría. La sospecha a propósito de la certeza y de la evidencia sólo tiene sentido si se piensa la racionalidad, la verdad, como absolutamente dependiente de la voluntad omnipotente de Dios. Sólo se puede considerar la posibilidad de un Deus deceptor - o genio maligno, como se prefiera- si Dios es pensado fundamental y fundacionalmente como Deus creator, pues la consideración de la teoría acerca de «los principios del conocimiento» como parte principal de la metafísica tiene su asiento en la hipótesis según la cual podemos dudar de todo aquello de lo que tengamos una razón, por mínima que sea, para dudar -y, así, comenzar a filosofar-,

[...] principalmente, porque hemos oído decir que Dios, que nos ha creado, puede hacer todo lo que le place, y porque todavía no sabemos si ha querido hacernos de tal manera que estemos siempre engañados, incluso acerca de las cosas que pensamos conocer mejor 15

Parece indudable que el momento inicial de la «verdadera filosofía» exige y a la vez da sentido - esto es, presupone- a una determinada concepción de Dios. Aunque el «primer principio de la filosofía» no esté aparente o explícitamente en idea alguna de Dios...

«Dios, que nos ha creado, puede hacer todo lo que le place». En esta afirmación queda como condensada, así pues, la condición de la puesta en marcha de la metafísica. La infinitud de la naturaleza de Dios y la indiferencia de su voluntad -o sea, su libertad en sentido propiamente cartesiano- van a determinar una concepción de la verdad que caracteriza propia, definitivamente 16 el pensamiento del autor de las Meditaciones metafísicas; concepción que se expresa en su teoría de la creación de las verdades eternas, y en la que transparece con claridad diáfana una concepción de Dios original que va a determinar no sólo todo el desarrollo de su metafísica, sino también, real, efectivamente, como señalaremos al final de estas páginas, los rumbos de la filosofía más sistemática del siglo. Encontramos una de sus formulaciones más completas en las Respuestas a las sextas objeciones:

Cuando consideramos atentamente la inmensidad de Dios, vemos manifiestamente que es imposible que no haya nada que no dependa de Él, no solamente entre todo lo que subsiste, sino incluso que no haya orden, ni ley, ni razón de la bondad ni de la verdad

\footnotetext{
15 AT, IX-2, 27.

16 Así lo estiman É. Boutroux (op. cit. pp. 131-136), J.-L. Marion (op. cit., pp. 11-12), É. Gilson, La liberté chez Descartes et la théologie, París, Alcan, 1913, p. 157, B. Rousset, Spinoza lecteur des Objections faites aux Méditations de Descartes et de ses Réponses, París, Kimé, 1996, pp. 66-67. En contra de esta apreciación se posiciona, por el hecho de aparecer en lugares considerados como marginales de la obra de Descartes -aunque confesamos no saber cuál puede ser el criterio de la discriminación-, M. Gueroult, Descartes selon l'ordre des raisons, I, París, Aubier, 1953, p. 24.
} 
que no dependa de Él; de otro modo [...] no habría sido totalmente indiferente para crear las cosas que ha creado. 17

Todo lo que es, esencias y existencias, ha sido creado por Dios. El Dios de Descartes es un Dios esencialmente creador. Y el acto de la creación divina parece suponer una cierta indiferencia, o, mejor, una cierta indeterminación. La voluntad de Dios instaura el bien y la verdad; Dios, por tanto, debe hallarse situado más allá del bien y de la verdad. Su trascendencia respecto de bien y verdad es en cierto sentido esencial: el hecho definitorio de que Dios haya creado todas las cosas, todo lo que es, se seguirá de sus propios atributos y de la manera como serán definidos 18 . Pues bien, lo que nos importa en este punto es seguir un orden y comenzar por los escritos en que se opera este significativo cambio de registro, el descubrimiento de una «dimensión del ser», que va a determinar todo el desarrollo de la metafísica del francés, incluida esa suerte de punto de apoyo en que consiste el descubrimiento del estatuto ontológico y epistemológico del cogito. ${ }^{19}$

La doctrina de la creación divina de las verdades eternas irrumpe con la fuerza devastadora de una auténtica revolución teórica en las cartas que Descartes escribe a Marin Mersenne en la primavera de 1630: en ellas se ofrece por vez primera el programa -que con el tiempo será desarrollado, pero que en sus rasgos esenciales aparece aquí en una forma acabada, permaneciendo intacto a lo largo de toda su biografía intelectual20 - de su reflexión propiamente filosófica. Programa que, ciertamente, supone un giro radical en el quehacer que hasta este momento le ha mantenido ocupado. En primer lugar, y al margen de la consideración de las verdades morales a que se alude en el texto de las Respuestas a las sextas objeciones, se afirma en dicha correspondencia que Dios crea las verdades matemáticas, ofreciéndose con ello una concepción de la naturaleza de Dios, del fundamento ontológico de

\footnotetext{
17 AT, IX, 235.

18 Cf. H. Gouhier, La pensée métaphysique de Descartes, París, Vrin, 1999 (1962), pp. 181 y ss.

19 Tal es una de las tesis del trabajo de Ferdinand Alquié sobre el descubrimiento metafísico del hombre en Descartes. Para Alquié, en efecto, el momento en el que se produce tal cambio de registro es perfectamente datable: «[...] c'est aux environs de 1629 que Descartes découvre une dimension de l'Être que les Regulae et ses travaux scientifiques semblent avoir ignorée et qui se révèle, en sa sublime profondeur, dans la lettre où, le 15 avril 1630, Descartes fait part à Mersenne de sa théorie de la création des vérités éternelles. C'en est alors fini de toute suffisance de l'objet, et le Monde étalé sur un plan, où se confondaient objets physiques et objets mathématiques, apparaît soudain sur l'arrière fond ontologique qu'il suppose. Pourtant, le cogito n'est pas formulé. Mais la démarche dont il naîtra s'amorce et se précise» (La découverte métaphysique de l'homme chez Descartes, Paris, P.U.F, 2000 (6 ed.), p. 83). Voluntarismo y creacionismo divinos $-\mathrm{y}$, con ellos, trascendencia del fundamento ontológico de todo lo que es-, por tanto, como condición de posibilidad de todo el recorrido filosófico de nuestro autor.

20 Cf. É. Boutroux, Des vérités éternelles chez Descartes, op. cit., p. 42. Prueba de ello son los textos que convocaremos a lo largo de estas páginas, los cuales abarcan el período comprendido entre la primavera de 1630 y el verano de 1648 .
} 
todas las cosas, sobre la que gravitan unas consecuencias de la máxima densidad conceptual. El 15 de abril de 1630, nuestro autor se muestra exultante; está convencido de haber descubierto una suerte de tierra firme:

[...] estimo que todos aquellos a quienes Dios ha concedido el uso de esta razón [humana, natural], están obligados a emplearla principalmente en intentar conocerle y conocerse a sí mismos. Es por aquí por donde he tratado de comenzar mis estudios, y os diré que no habría podido encontrar los fundamentos de la física si no los hubiese buscado por esta vía [...]; pienso haber encontrado, por lo menos, cómo se pueden demostrar las verdades metafísicas de una manera que es más evidente que las demostraciones de la geometría [...] no dejaré de tocar en mi física varias cuestiones metafísicas, y particularmente ésta: que las verdades matemáticas, a las que vos llamáis eternas, han sido establecidas por Dios y dependen enteramente de Él, tanto como el resto de las criaturas. En efecto, decir que estas verdades son independientes de Él es hablar de Dios como de un Júpiter o de un Saturno, y someterle al Éstige y los Destinos. [...] es Dios quien ha establecido estas leyes en la naturaleza de la misma manera que un rey establece las leyes en su reino ${ }^{21}$

Son varios los aspectos de este fragmento sobre los que debemos detenernos: (I.) la indudable intención apologética que lo anima; (II.) la concepción de las relaciones que entre sí mantienen la física y la metafísica que anuncia; (III.) la teoría acerca de la dependencia de las verdades eternas respecto de Dios que señala; (IV.) la vinculación que propone entre el acto creador divino y una cierta teoría fundamental de la causalidad; y (V.) la concepción de la naturaleza de Dios -y (VI.) de la verdad- que se abre paso expresándose a través de una metáfora que gozará de especial fortuna a lo largo de todo el siglo XVII.22

\footnotetext{
21 AT, I, 144-145.

22 Esta imagen de un Dios que establece las leyes naturales del mismo modo que un soberano establece las leyes civiles, adquiere una fuerza renovada a lo largo de los siglos XVII y XVIII, los siglos del absolutismo. A través de ella son pensadas de manera conjugada, análogamente, soberanía humana y potencia divina. La novedad en el empleo cartesiano de esta metáfora no está, como es obvio, en el hecho de que sea el francés quien la haya forjado, pues la imagen de un Dios legislador es tan antigua como las Sagradas Escrituras mismas. La novedad está más bien en que en la obra cartesiana queda vinculada a la problemática en torno a la cual nuestro autor está construyendo la «nueva filosofía». En efecto, Descartes incorpora a una polémica «nueva», acerca de los «principios del conocimiento» y de su fundamentación, una metafórica tal vez más propia de una época esencialmente teológica, de una época, dicho claramente, que en principio parecería cancelada por el mero hecho de haber estado vinculada al escolasticismo y aristotelismo contra los que esa «nueva filosofía» se está posicionando consciente y combativamente. Nuestra hipótesis es que con ello Descartes no hace sino resignificar o reconceptualizar una cuestión teológica -la de la creación- convirtiéndola en cuestión metafísica fundamental -la de la potencia de Dios o del primer principio en el orden del ser-, de manera que una cuestión propia de una época del pensamiento que se comienza a percibir como definitiva y conscientemente superada, sobrevive en esta otra, en la época de la supuesta autonomía e independencia de la «luz natural», como cuestión igualmente decisiva. Quizás la ruptura de nuestro autor con el pasado,
} 
I. En primer lugar -y, si se quiere, lateralmente-, una cierta intención apologética23, que jamás abandonará la escritura cartesiana, transparece ya en estas cartas y en las complementarias de los días 6 y 27 de mayo de aquel mismo año. Pensar a Dios como creador de todas las cosas -no sólo de su existencia, sino también de las verdades matemáticas o eternas, esto es, de las esencias ${ }^{24}-$, o, lo que veremos que es lo mismo, «saber» su incomprensibilidad, equivale a corregir una «manera de hablar» de Dios que para los sensibles oídos del francés no puede sino ser indigna 25 . Tres semanas más tarde insistirá en lo mismo: decir que la verdad de algo es independiente de la voluntad de Dios -decir, por ejemplo, que la identidad lógica o la conexión necesaria de que son acreedoras las verdades matemáticas constituyen el solo fundamento de la racionalidad- equivale a «blasfemar» 26 , es una manera de hablar que conduce rápida y directamente al ateísmo:

Quienes no poseen pensamientos más elevados que éstos pueden convertirse fácilmente en ateos, y, dado que comprenden perfectamente las verdades matemáticas, pero no

en la que tanto insiste -nemo ante me, repite, inasequible al desaliento-, deba ser contemplada desde una cierta distancia crítica. Por lo demás, tal vez sería interesante poner en relación las afirmaciones que Carl Schmitt hace a propósito de estas cartas en Teología política (Madrid, Trotta, 2009, cap. 3) con lo que el jurista alemán dice acerca de la forma de las diferentes épocas por las que atraviesa el pensamiento y los trasvases conceptuales entre ellas en su conferencia de 1929 «La era de las neutralizaciones y de las despolitizaciones» (recogido ahora en El concepto de lo político, Madrid, Alianza, 1998, esp. pp.109-114).

23 Acerca de este aspecto de la vida y la obra cartesiana, sobre el cual no podemos explicarnos prolijamente en este artículo, cf. el precioso trabajo de H. Gouhier, La pensée religieuse de Descartes, París, Vrin, 1972 (1924), cuya tesis es corroborada en el prefacio de 1972 a la segunda edición: «Descartes, me semblait-il, avait sincèrement cru que sa nouvelle physique et sa nouvelle métaphysique étaient naturellement accordées aux vérités de la foi chrétienne, qu'en renonçant à l'aristotelisme scolastique les théologiens ne perdraient rien au change, que la substitution d'une philosophie à une autre était parfaitement légitime si l'on comprenait bien les rapports de la raison et de la foi tels que saint Thomas les avait définis: par suite, servir le cartésianisme, c'était servir la religion [...] apologétique cartésienne et apologétique religieuse n'étaient pas distinctes dans sa pensée; partir à la conquête des écoles et à la conquête du monde, c'était aussi travailler ad majorem Dei gloriam» (p. 9) 24 Cf. la carta a Mersenne del 27 de mayo de 1630: «[...] es cierto que Él es autor tanto de la esencia como de la existencia de las criaturas. Ahora bien, esta esencia no es otra cosa que esas verdades eternas, las cuales no concibo yo que emanen de Dios como los rayos [lo hacen] del sol, sino que sé que Dios es autor de todas las cosas, y que estas verdades son una cosa, y, en consecuencia, que Él es su autor. Digo que lo sé, y no que lo concibo, ni que lo comprendo... » (AT, I, 152). Acerca de la polémica en que se inscribe la negación de que las verdades eternas emanen de Dios «como los rayos del sol», cf. J.-L. Marion, Sur la théologie blanche de Descartes, op. cit., pp. 140-159.

25 AT, I, 146: «[...] me sería muy grato conocer las objeciones que se puedan hacer, y también que el mundo se acostumbrase a escuchar hablar de Dios con más dignidad, a lo que me parece, de la que emplea el vulgo, el cual le imagina casi siempre como una cosa finita».

26 Carta a Mersenne del 6 de mayo de 1630: «[...] si los hombres entendiesen bien el sentido de sus palabras, jamás podrían decir sin blasfemar que la verdad de algo precede al conocimiento que Dios tiene de ello, pues en Dios querer y conocer es sólo uno...» (AT, I, 149). 
la de la existencia de Dios, no es asombroso que no crean que aquéllas dependen de ésta. 27

II. Pero más importante para nuestros propósitos es constatar que la teoría aquí propuesta desempeña una función decisiva en la construcción del prestigio filosófico de la ciencia cartesiana, de la «nueva ciencia» en general: con dicho conjunto de cartas queda expresada una preocupación acuciante por los fundamentos metafísicos de la física; la metafísica debe proporcionar a la ciencia una solidez de la que los principios de ésta carecen por sí mismos. Tal solidez sólo podrá ser adquirida a través de una justificación a priori de esos principios, de una justificación por sus causas: se debe partir de un cierto conocimiento de la naturaleza de Dios, principio creador del mundo físico y, a idéntico título, de su estructura lógica y moral.28 Esta doctrina constituirá, por decirlo con Étienne Gilson, la indispensable base metafísica de una física de las causas eficientes ${ }^{29}$. Definitivamente, la teoría de la creación divina de las verdades eternas comunicada a Mersenne del 15 de abril de 1630 muestra la estrecha solidaridad que une los trabajos científicos y las meditaciones metafísicas de Descartes ${ }^{30}$.

Así, lo que finalmente significa esta correspondencia, en este respecto, es la no elevación de la física a metafísica, la imposibilidad de otorgar a la estructura del mundo natural algún tipo de autonomía ontológica: su orden carece por sí mismo de su fundamento último, éste no se halla ni en las cosas ni en la forma de sus relaciones. Se encuentra en la voluntad de Dios, ente absolutamente omnipotente que instaura la necesidad lógica y natural creando las verdades eternas en virtud de un acto soberano de su voluntad, la cual, por consiguiente, es anterior e independiente de dicha necesidad; o sea, la trasciende. La estructura racional inmanente del mundo físico sólo se sostiene desde una trascendencia ajena en su esencia, como veremos, a las leyes de aquella estructura. Pero lo que a nosotros realmente nos interesa dentro de los límites de este trabajo es que con dicha teoría se expresa con toda su fuerza una concepción de la naturaleza de Dios y de la verdad que va a ser esencial en toda la metafísica nuestro autor. Y, derivadamente, también en la del siglo; ciertamente a partir de aquella teoría y de esa concepción de la potencia divina se organizará el campo de fuerzas en lucha en que se construye y desarrolla la gran filosofía del XVII.

\footnotetext{
27 AT, I, 150. Sobre este pasaje, cf. J.-M. Beyssade, La philosophie première de Descartes, op. cit., p. 104.

28 Sobre la articulación entre física y metafísica en Descartes a propósito de esta carta, cf. J.-M. Beyssade, «Tout-puissance de Dieu et nécessité des principes physiques», recogido ahora en Études sur Descartes. L'histoire d'un esprit, París, Éditions du Seuil, 2001, pp. 54-79.

29 Cf. Étienne Gilson, La liberté chez Descartes et la théologie, op. cit., p. 94.

${ }^{30} \mathrm{Y}$ ello en cuanto a su descubrimiento, su exposición y sus principios. Cf. H. Gouhier, La pensée religieuse de Descartes, op. cit., p. 76.
} 
III. En efecto, ¿qué significa que las verdades matemáticas, lógicas, físicas y morales sean instituidas libremente por Dios? Primero, que la necesidad racional no es absoluta, al menos desde un punto de vista divino. Sólo introduciendo las verdades en la esencia de Dios podrían ser éstas consideradas como absolutamente necesarias, pues nada absolutamente necesario podría existir fuera de Dios mismo. Sin embargo, afirmar que éste las crea equivale a postular clara y distintamente su absoluta independencia, y la de su acto creador, su anterioridad lógica y ontológica, respecto de aquellas verdades. Digámoslo a la inversa: lejos de ser independientes y necesarias en sentido incondicionado o absoluto, las verdades eternas dependen absolutamente de Dios, de su voluntad omnipotente. Pues proceden de ella. Dios, por tanto, se halla necesariamente situado más allá del bien y de la verdad debido a que instaura, creándolos libre, indiferentemente, tanto el uno como la otra. Esto es lo que en el fondo significa que la existencia de Dios es la primera y más eterna de todas las verdades, que en ella se originan todas las demás:

[...] la existencia de Dios es la primera y la más eterna de todas las verdades que pueden ser, y la sola de la que proceden todas las demás. Pero lo que hace que sea fácil equivocarse en esto es que la mayor parte de los hombres no considera a Dios como un ser infinito e incomprensible, y que es el solo autor del que todas las cosas dependen. ${ }^{31}$

El Dios de Descartes sólo puede ser pensado como un Dios-autor, como un Dios del todo distinto de su obra, como un Dios-sujeto-voluntad que es infinito -en el sentido, de momento, de que nada puede determinar o limitar su acción creadoray del que todo lo que es depende como de su causa o principio. O sea, como un Dios de cuya voluntad depende incluso la sintaxis, la estructura lógica y racional, de su creación.

La consecuencia más inmediata que podemos extraer de esta primera aproximación es que el creacionismo divino se convierte en un principio que por sí mismo debe extenderse a todo necesariamente, pues no puede admitir ningún tipo de excepción ni de atenuación. Si todo, salvo Dios, es criatura, no habrá más que una sola manera de ser creado: todo lo que es, sea contingente -las existencias, las cosas que actualmente existen-, sea necesario -las verdades eternas-, ha debido ser igualmente creado por Dios, y ha debido serlo del mismo modo. El acto de la creación es un acto único del cual depende el ser de todo lo que es, sea como sea eso que es ${ }^{32}$. Y con una afirmación semejante no puede dejar de afirmarse simultáneamen-

\footnotetext{
31 AT, I, 150.

32 Cf. H. Gouhier, La pensée métaphysique de Descartes, op. cit., p. 245: «La création est un acte unique: ou la nécessité des essences signifie qu'elles ne sont pas créées, comme dans la perspective augustinienne, et la création contingente porte sur les existants dont ces essences sont les modèles; ou les essences sont créées, et la création, également contingente, les fait apparaître en même temps que les existants dont elles fixent les structures»; J.-L. Marion, Sur la théologie blanche de Descartes, op.
} 
te la necesaria transcendencia de Dios respecto de su creación. Ni siquiera la verdad puede confundirse con la esencia divina; ésta es ajena o exterior a la racionalidad misma. Dios, en efecto, podría haber hecho, o, mejor, «decretado», que «no fuera verdad que todas las líneas que salen del centro de la circunferencia sean iguales», que cuatro más cuatro no fuese igual a ocho, de la misma manera que podría no haber «creado el mundo» ${ }^{33}$, sin que por ello se viese modificada su naturaleza o esencia. Esto es, sin que por ello fuese preciso pensarla de otra forma. Volvamos a las Respuestas a las sextas objeciones:

Es también inútil preguntarse cómo podría haber hecho Dios desde toda la eternidad que dos veces 4 no hubiesen sido 8, etc., pues confieso que nosotros no podemos comprender esto; pero, puesto que, por otro lado, comprendo muy bien que nada puede existir, en cualquier género de ser que sea, que no dependa de Dios, y que le ha sido muy fácil ordenar de tal manera ciertas cosas que los hombres no puedan comprender que han podido ser de otro modo de como son, sería totalmente contrario a la razón dudar de las cosas que comprendemos muy bien a causa de algunas otras que no comprendemos, y las cuales no vemos que deban ser comprendidas. Así, por tanto, no hay que pensar que las verdades eternas dependen del entendimiento, o de la existencia de las cosas, sino sólo de la voluntad de Dios, quien, como un legislador soberano, las ha ordenado y establecido desde toda la eternidad 34 (subrayado del autor).

El orden y establecimiento o institución de las verdades eternas (y de verdades que expresan una necesidad aparentemente inconmovible), dice este texto, dependen de la voluntad «soberana» de Dios, no de un entendimiento, de una ratio en la que quedase cifrada la necesidad racional y que determinase a la voluntad de Dios a crear ciertas cosas, ciertas verdades, pero no otras. Al pensar el fundamento de todo lo que es, Descartes rechaza que la razón pueda ser considerada como instancia fundadora. La razón, la verdad, debe ser ella misma fundada, instaurada, y sólo puede serlo por la voluntad infinita, desvinculada, absolutamente indiferente y por tanto libre de Dios. La razón, así, no puede ser principio, en el sentido de fundamento, del ser. La causa de todo lo que es no se puede indentificar con ratio alguna; consiguientemente, todo aquello que se manifieste como ratio jamás podrá ser considerado absolutamente como causa. La teoría de la creación de las verdades

cit., pp. 138 y 272, y Jean-Marie Beyssade, La philosophie première de Descartes. Le temps et la cohérence de la métaphysique, París, Flammarion, 1979, p. 107: «L'essentiel est que tout ce qui n'est pas Dieu a avec Dieu un seul et même rapport, que tout en dépend "en même façon», et qu'Il ne dépend lui-même de rien. Dès 1630, les vérités éternelles ne sont pas moins dépendantes de Dieu que ces autres créatures que sont les choses existantes».

33 Cf. Carta a Mersenne del 27 de mayo de 1630: «[...] [Dios] ha sido tan libre de hacer que no fuese verdad que todas las líneas trazadas desde el centro hasta la circunferencia fueran iguales, como de no crear el mundo. Y es cierto que estas verdades no están más necesariamente unidas a su esencia que las demás criaturas» (AT, I, 152).

34 AT, IX, 236. 
eternas, decíamos más arriba, equivale a una cierta teoría fundamental de la causalidad. Y a una teoría del fundamento de la causalidad, decimos ahora, que desvincula esencialmente a dicho fundamento o principio de la estructura misma de la racionalidad.

IV. La idea de creación es introducida, obviamente, a modo de una cierta teoría de la causalidad: crear es causar el modo de ser de las cosas que son; sólo Dios es absolutamente creador de todo lo que es. Lo cual significa, repitámoslo, que el fundamento, el principio de todo lo que es, se halla situado más allá de la razón, que la causa-Dios- no es nunca ratio -ésta es criatura-. Si el fundamento o causa de todo lo que es crea las verdades eternas siendo así trascendente a la necesidad racional, entonces toda inteligibilidad, por el hecho de sernos racionalmente accesible, quedará eo ipso despojada del estatuto de fundamento último ${ }^{35}$.

Todo indica, así pues, que lo que está en juego tras la introducción de la teoría de la creación de las verdades eternas es una reflexión de carácter metafísico sobre la causalidad. Y sobre una causalidad que pretende explícitamente, como decíamos más arriba, ser total. Invirtiendo una afirmación de Henri Gouhier, podríamos sostener que bajo la relación que la metafísica judeo-cristiana, y cartesiana, denomina «creación», lo que se está poniendo en juego es la dependencia ontológica que se establece en todo proceso fundamental de causación ${ }^{36}$. Dependencia que aquí es considera como total y que puede o debe ser pensada como la expresada por la causalidad de tipo eficiente: si las verdades eternas son creadas por Dios, otorgándoseles de esta manera el mismo estatuto de criaturas que al resto de cosas creadas -la creación es un acto único-, el tipo de causalidad que parece exigir el acto creador divino será también único: el de la sola causalidad eficiente. Ésta, por tanto, será total. Volvamos a las cartas remitidas a Mersenne en la primavera de 1630:

Me preguntáis in quo genere causae Deus disposuit aeternas veritates? Os respondo que lo ha hecho in eodem genere causae por el que ha creado todas las cosas, es decir, ut efficiens \& totalis causa. Pues es cierto que Él es el autor tanto de la esencia como de la existencia de las criaturas. Ahora bien, esta esencia no es otra cosa que esas verdades eternas, las cuales no concibo yo que emanen de Dios como los rayos [lo hacen] del sol, sino que sé que Dios es autor de todas las cosas, y que estas verdades son una cosa, y, en consecuencia, que Él es su autor. ${ }^{37}$

35 Cf. J.-L. Marion, Sur la théologie blanche de Descartes, op. cit., pp. 28 y ss., y Vincent Carraud, Causa sive ratio. La raison de la cause, de Suarez à Leibniz, París, P.U.F., 2002, pp. 288-293.

36 Cf. H. Gouhier, La pensée métaphysique de Descartes, op. cit., p. 180: «Sous le nom de cause, la relation mise en jeu est cette dépendance dans l'être que la métaphysique judéo-chrétienne appelle création...».

37 AT, I, 152. 
Dios, por tanto, es causa eficiente y total de todo lo que es, y todo lo que es se halla sometido en la causación de su ser a la regla de la causalidad eficiente, la cual se revela como universal: la causalidad eficiente puede ser total, y para pensar una causalidad total es suficiente la pura y simple eficiencia ${ }^{38}$. La omnipotencia y la infinitud de Dios lo avalan. Pero de lo que se trata con ello es de poder comenzar a esclarecer algunos atributos esenciales de Dios. Lo realmente importante a propósito de esta teoría acerca de las verdades eternas, ha señalado con fuerza É. Boutroux, es que con ella se salvaguarda la libertad absoluta de Dios -y su perfección-, lo cual pasa necesariamente por concebir las esencias como libremente creadas, de manera que Dios no pueda ser pensado como un sujeto constreñido en manera alguna por la necesidad de que es acreedor $-\mathrm{y}$ que se impone a todo sujeto racional- cualquier sistema de verdades eternas ${ }^{39}$. Sostener lo contrario equivaldría, utilizando los términos empleados por el mismo Descartes, a convertir a Dios «en un Júpiter o en un Saturno», a someterle «al Éstige y al Destino», a atenuar su libertad, a concebirlo como un ente de algún modo limitado y, por tanto, imperfecto. Lo cual no sólo es «blasfemo», sino también - ¿por ello?- imposible desde estos presupuestos. En efecto, ¿qué podría determinar a la voluntad fundante de Dios?, ¿qué podría «necesitar» a Dios a crear ciertas verdades pero no otras, incluso contradictorias con las que efectivamente ha creado? La respuesta sólo puede ser clara y tajante: nada. Un Dios-autor vinculado a su obra de modo indiferente ha de ser libre en sentido absoluto. La acción divina no puede estar constreñida por nada que no sea la forma de esa acción misma:

Preguntáis también quién ha necesitado a Dios a crear estas verdades. Y yo digo que ha sido tan libre de hacer que no fuese verdad que todas las líneas tiradas desde el centro hasta la circunferencia fueran iguales, como de no crear el mundo. Y es cierto que estas verdades no están más necesariamente unidas a su esencia que las demás criaturas. Preguntáis qué ha hecho Dios para producirlas. Digo que ex hoc ipso quod illas ab aeterno esse voluerit \& intellexerit, illas creavit, o bien (si no atribuís la palabra creavit más que a la existencia de las cosas) illas disposuit \& fecit. Pues en Dios es una misma cosa querer, entender y crear, sin que una preceda a la otra, ne quiden ratione 40

Querer, entender, crear... Estos tres actos son reductibles a uno solo, siéndole otorgado el protagonismo en todos los textos de que nos estamos ocupando a la

38 Cf. J.-L. Marion, Sur la théologie blanche de Descartes, op. cit., pp. 149-150. Sobre la generalización de la causalidad eficiente, mecánica, en Descartes, cf. Elhanan Yakira, La causalité de Galilée à Kant, op. cit., pp. 27-35.

39 Cf. É. Boutroux, Des vérités éternelles chez Descartes, op. cit., p.75: «[...] ce système de vérités éternelles se compose de parties si étroitement dépendantes les unes des autres, si bien nouées et enchaînées qu'elles ne laissent plus la moindre place pour l'action libre. C'est pourquoi ce serait nier la liberté et la perfection de Dieu que d'admettre la présence en lui de ces vérités comme en un sujet» 40 Carta a Mersenne del 27 de mayo de 1630 (AT, I, 152-153). 
voluntad, y no sólo porque éste sea el término utilizado en todos los pasajes en que Descartes trata de la creación de las verdades eternas, sino principalmente porque el acto único de la creación, de la instauración de todo lo que es y de las leyes según las cuales todo lo que es se comporta, apela a una potencia que sólo puede ser denominada voluntad, no entendimiento. La ratio, ya hemos insistido suficientemente en ello, no es fundadora, sino fundada. Así, las verdades eternas son

tanto verdaderas cuanto posibles sólo porque Dios las conoce como verdaderas o posibles; pero, por el contrario, no digo que sean conocidas por Dios como verdaderas a la manera de verdades que existiesen independientemente de Él41.

Repitámoslo: lo que hace posible pensar la dependencia de la racionalidad respecto de Dios es la omnipotencia, es decir, la voluntad de Dios, la cual puede ser identificada con su entendimiento tan sólo porque en virtud del mismo acto por el que «quiere» ciertas verdades, las instaura, esto es, las «crea»; es decir, porque la creación divina no es gobernada por un conjunto de ideas, de verdades, que determinaría qué es posible o deseable crear; porque dicho sistema no precede a la voluntad u omnipotencia de Dios, ni, por tanto, puede ser independiente de ella.

V. Así pues, retomando el hilo de nuestra argumentación, lo que nos encontramos en esta correspondencia es un cierto espíritu apologético; una fundamentación metafísica de los principios de la física; una teoría de la dependencia de la verdad respecto de la voluntad divina; una consideración del acto fundante de la indeterminada voluntad de Dios como principio último de la relación causal que vincula al creador con todas sus criaturas de un modo idéntico... Todos estos principios parecen situar la potencia de Dios en una trascendencia casi absoluta. Es urgente determinar ahora cómo la idea de esta trascendencia del principio de todo lo que es queda definitivamente blindada a partir de la consecuencia tal vez más radical que puede extraerse de esta teoría. Tal consecuencia extrema es la siguiente: la naturaleza de Dios, todos sus atributos, sólo puede revelarse, al igual que su voluntad, como algo de suyo incomprensible. Ahora bien, esta idea, verdadero principio dentro del sistema, será el punto a partir del cual se hará posible, de una manera paradójica tan sólo en apariencia, encontrar una fundamentación sólida para la racionalidad misma... Vayamos por partes.

Sabemos ya que el ser de la racionalidad, de la verdad, mantiene una relación de dependencia directa y única con la voluntad indiferente, con la potencia infinita u omnipotencia de Dios. Y sabemos también que la identificación estricta de la causación en sentido absoluto con el concepto de «creación» veda inevitablemente toda comprensión racional del fundamento - de la causa o principio creador- y de su vin-

41 Carta a Mersenne del 6 de mayo de 1630 (AT, I, 149). 
culación con lo fundamentado - con lo causado o creado-. Pues bien, omnipotencia e ininteligibilidad guardan una relación necesaria que conforma una tesis definitiva del pensamiento cartesiano del fundamento: sólo en referencia a la incomprensibilidad puede la omnipotencia ser fundadora. En la raíz misma de la teoría de la creación de las verdades eternas late un sentimiento ${ }^{42}$, una «concepción» de la ininteligible omnipotencia de Dios, que va a ofrecer el resquicio por el cual sortear la amenzaza del fracaso en la fundamentación total de la verdad. La omnipotencia de Dios no puede pertenecer a lo inteligible, pero precisamente por ello podrá fundar la inteligibilidad misma.

Acabamos de ver que Dios es pensado como causa «eficiente y total» de todo lo que es, y que lo es a idéntico título. Y Descartes pensará la causalidad eficiente según los cánones dictados por cierta tradición ${ }^{43}$ : el efecto debe diferir de su causa, y debe hacerlo irreductiblemente 44 . De momento empecemos por lo esencial: si la consideración de la causalidad eficiente impone la distinción, la irreductibilidad de causa y efecto, y si Dios es causa eficiente de las verdades eternas en virtud de su omnipotencia, las verdades eternas nada podrán enseñarnos acerca de la naturaleza de Dios, de la misma manera que no pueden decirnos nada acerca de la potencia o del poder en virtud del cual Dios crea todo lo que es. Con lo cual se significa nuevamente, aunque haciendo visible el aspecto más fundamental de la cuestión, la trascendencia divina: su trascendencia respecto de la racionalidad en el sentido de que Dios trasciende la inteligibilidad enteramente y es irreductible a ella. Dicho de otra manera, ninguna ciencia puede haber que nos permita comprender a Dios. De ahí que todos los pasajes en que se aborda esta teoría de la creación de las verdades eternas se vean acompañados de reflexiones más o menos precisas, más o menos elaboradas, sobre la ininteligibilidad de la naturaleza divina, sobre la inconmensurabilidad entre la naturaleza infinita de Dios y la finitud de nuestro entendimiento.

Dichas reflexiones, en efecto, desembocarán en un principio que va a acelerar decisivamente la reflexión en muchos textos canónicos de nuestro autor. Por ejemplo, en la tercera de las Meditaciones metafisicas, cuando el orden de las razones exija definir la serie de atributos que pertenece a la naturaleza de Dios:

\footnotetext{
42 Cf. H. Gouhier, La pensée religieuse de Descartes, op. cit., p. 81.

43 Cf. J.-L. Marion, Sur la théologie blanche de Descartes, op. cit., pp. 432-433.

${ }^{44}$ Lo cual, dicho sea de paso, situará a Descartes en una posición extremadamente difícil cuando intente explicar ante Arnauld su afirmación según la cual Dios es causa sui, viéndose obligado a introducir la analogía en su consideración de la causalidad eficiente, único medio de que dispone el entendimiento finito del hombre para comprender la incomprensible fuerza de que Dios dispone para existir por sí mismo. Cf. las Cuartas objeciones a las Meditaciones (AT, IX, 160-167), y sus Respuestas (AT, IX, 179-190).
} 
Por el nombre de Dios entiendo una sustancia infinita, eterna, inmutable, independiente, omnisciente, omnipotente, y en virtud de la cual yo mismo, y todas las demás cosas que son $[\ldots]$, han sido creadas y producidas 45

A partir de esta definición de Dios se hará preciso afirmar que la serie de atributos que la dan cuerpo está fuera del alcance del entendimiento del hombre. La incomprensibilidad de la naturaleza divina dependerá, o, mejor, vendrá exigida, por la noción misma de infinito, noción tan incomprensible como necesaria en la construcción de este sistema para abordar la cuestión de las relaciones del entendimiento del hombre con una de las ideas que encuentra cuando inspecciona los contenidos de su conciencia. La comprensión de dicha idea se mostrará como inalcanzable para toda conciencia finita por definición.

Sin embargo, lo realmente valioso en este esfuerzo de sistematización de la trascendencia de Dios es la sutil elaboración cartesiana del principio según el cual podemos disponer de una idea clara y distinta de aquello cuya naturaleza no podemos en modo alguno comprender. Es de esta manera como el curso de la reflexión alcanza un punto de aceleración que determina el blindaje absoluto y definitivo de la trascendencia de Dios. En las Meditaciones, la idea de Dios que el cogito halla en sí mismo se le puede mostrar como clara y distinta en cierto sentido, y, por consiguiente, como verdadera:

La idea, digo, de este ser soberanamente perfecto e infinito es enteramente verdadera [...] Esta misma idea es también muy clara y distinta, pues todo lo que mi ingenio concibe clara y distintamente de real y de verdadero, y que contiene en sí alguna perfección, está contenido en su totalidad en esta idea. 46

El cogito, pues, puede saber que una de sus ideas es verdadera; que esa idea no puede sino haber sido producida por el ente que constituye su objeto; que tal ente, por tanto, existe necesariamente -tal es, en sus líneas más generales, el movimiento deductivo de la existencia de Dios en esta Meditación-. Ahora bien, lo decisivo aquí es que se puede saber la verdad de semejante idea aun cuando el cogito no pueda comprender la naturaleza del ente representado por ella, aun cuando esa idea sea esencialmente, por su propia forma o naturaleza, incomprensible:

Y esto no deja de ser verdad, incluso aunque yo no comprenda lo infinito, o aunque haya en Dios una infinidad de cosas que yo no puedo comprender, ni tal vez tampoco alcanzar de ningún modo mediante el pensamiento; pues es propio de la naturaleza de lo infinito que mi naturaleza, que es finita y limitada, no lo pueda comprender. ${ }^{47}$

\footnotetext{
45 AT, IX, 35-36.

46 AT, IX, 36.

47 AT, IX, 37.
} 
La única relación que un entendimiento finito puede mantener con la idea de una naturaleza que se muestra a ese mismo entendimiento como infinita, no puede sino ser una relación de necesaria incomprensibilidad. Se puede demostrar la existencia de Dios porque el cogito encuentra entre sus ideas una que no puede haber producido él mismo; dada la magnitud de tal idea, la deducción que establece la existencia del objeto ideado sólo puede ser verdadera: Dios existe formal y objetivamente. Pero aquí se detiene nuestra comprensión de Dios; sólo podemos saber que es un ente que posee todas las perfecciones que somos capaces de pensar o de hallar en nosotros mismos, y que las posee en acto y elevadas al infinito. Esto es, podemos «saber» que las posee de un modo que es imposible «comprender».

Pues bien, el principio que permite a Descartes no pensar como un obstáculo insalvable para la positividad de la metafísica este desajuste entre dos naturalezas inconmensurables -la naturaleza infinita de Dios y la naturaleza finita del entendimiento- se encuentra indicado ya en las cartas dirigidas a Mersenne de que nos estamos ocupando: en ellas afirma que se debe distinguir desde el comienzo entre «saber»y «comprender». El 27 de mayo de 1630, previene a su corresponsal en los siguientes términos:

[...] se puede saber que Dios es infinito y omnipotente, aunque nuestra alma, siendo finita, no lo pueda comprender ni concebir -de la misma manera que podemos tocar con las manos una montaña pero no abrazarla como haríamos con un árbol o con cualquier otra cosa que no excediese el tamaño de nuestros brazos-. Pues comprender es abrazar con el pensamiento, pero para saber una cosa es suficiente con tocarla con el pensamiento. ${ }^{48}$

La noción de Dios puede ser «tocada» con el pensamiento, pero no «abrazada» por él. En relación con semejante noción lo más que podemos hacer es guiarnos, como los ciegos, mediante una suerte de sentido del tacto: podemos «saber»; pero no podemos ver, no podemos «comprender» o «concebir». Con esta distinción entre «comprender» y «saber» Descartes considera haber salvado los obstáculos que pudiera haber puesto a su programa de fundamentación del conocimiento el problema de la incomprensibilidad de la naturaleza del principio, fundamento o causa del ser de todas las cosas.

Así, con estas cartas se ofrece por vez primera en la escritura cartesiana una idea fundamental: Dios sólo puede ser pensado en la medida en que escapa a toda comprensión. Al ser el principio que todo lo instaura, incluida la racionalidad misma, y que instaura todo en función de su omnipotencia, Dios sólo puede ser pensado como Dios si no puede ser comprendido. De lo contrario, no podría ser reconocido como el creador de esencias y de existencias en que ha sido convertido. Por lo que atañe a Dios, en consecuencia, la relación que se establece entre su comprensibilidad y su

48 AT, I, 152. 
cognoscibilidad es inversamente proporcional, de modo que la comprensión cede terreno en la medida en que lo gana su conocimiento -el «saber» acerca de su naturaleza-. Y por ello el hecho de comprender que es imposible comprender a Dios hace de su idea una idea clara y distinta; ésta es clara y distinta, por decirlo con Henri Gouhier, en la medida en que representa una realidad que se sitúa más allá de toda representación clara y distinta, ${ }^{49}$ en la medida en que representa una realidad esencialmente ininteligible para un entendimiento finito. Lo claro y distinto en la idea de Dios, así pues, es el hecho de que Dios no puede ser comprendido ni clara ni distintamente, de manera que lo absolutamente contradictorio sería que el hombre -ser finito cuyo entendimiento es igualmente finito-comprendiese algo que es infinito. La incomprensibilidad constituye, en definitiva, la razón formal de lo infinito: la razón de su incomprensibilidad está contenida en su esencia ${ }^{50}$. Entender o comprender lo infinito, puesto que la incomprensibilidad está en su «razón formal», consiste en entender que es incomprensible. 51 La naturaleza de Dios no puede dejar de ser tan ajena a la racionalidad -tan incomprensible- como el acto creador divino mismo, pues no podemos sino ignorar cómo y por qué Dios crea todas las cosas. 52

Por tanto, en definitiva, la idea de un Dios cuya naturaleza, cuya voluntad, cuya potencia, es esencialmente incomprensible puede ser clara y distinta. Esto es, lo que se nos presenta clara y distintamente es la absoluta trascendencia de la naturaleza de Dios respecto incluso de la racionalidad. Y es esta idea de la trascendencia absoluta de Dios, precisamente, lo que va a desempeñar, como decíamos antes, la esencial función de fundamentar la validez, la solidez, de esa racionalidad que constitutivamente es incapaz de comprender aquella potencia y desde la cual sólo es posible una representación clara y distinta de la imposibilidad de acceder a toda representación clara y distinta de la potencia divina.

VI. El espesor conceptual de las consecuencias de todo lo anterior es ciertamente inmenso, pero lo que nos importa, para ir terminando con nuestros análisis, es que

49 Cf. H. Gouhier, La pensée métaphysique de Descartes, op. cit., pp. 212-214.

50 Cf. Respuestas a las quintas objeciones: «[...] es contradictorio que yo comprenda algo, y que eso que comprendo sea infinito; pues para tener una idea verdadera de lo infinito, no es de ninguna manera necesario que sea comprendido, y tanto más cuanto que la incomprensibilidad misma está contenida en la razón formal de lo infinito» (AT, VII, 368).

51 Cf. J.-M. Beyssade, La philosophie première de Descartes, op. cit., p. 104, y J. García López, El conocimiento de Dios en Descartes, op. cit., pp. 133-144.

$52 \mathrm{Cf}$. Meditación cuarta: «[...] no debo asombrarme si mi inteligencia no es capaz de comprender por qué Dios hace lo que hace, y, así, no tengo ninguna razón para dudar de su existencia porque tal vez vea por experiencia muchas otras cosas sin poder comprender por qué razón ni cómo las ha producido Dios. Pues, como ya sé que mi naturaleza es extremadamente débil y limitada, y que, al contrario, la de Dios es inmensa, incomprensible e infinita, no tengo ya dificultad alguna para reconocer que hay una infinidad de cosas en su potencia cuyas causas sobrepasan el alcance de mi ingenio» (AT, IX, 44). 
nos hallamos ya en condiciones de poder vislumbrar el sentido último de la recurrente metáfora con la que Descartes trata de explicar la manera como Dios instituye en la naturaleza y «en el corazón de los hombres» la estructura de la racionalidad. Es decir, nos hallamos en condiciones de comprender cómo encuentra un fundamento para la racionalidad -ésta está bien fundada, de modo que queda al amparo de todo ataque escéptico, a pesar de depender de una institución ajena a su estructura misma- partiendo de la teoría de la creación de las verdades eternas expuesta en la primavera del año 30. Gracias a ésta podrá comenzar a desarrollarse una teoría que también resultará decisiva en toda la obra de nuestro autor: la de la disposición innata en el cogito de determinadas ideas, leyes o estructuras.

Anteriormente hemos citado un texto de las Respuestas a las sextas objeciones en el que se emplea una imagen -Dios actúa «como un legislador soberano» (AT, IX, 236)- que aparece muy recurrentemente en la escritura de Descartes; imagen cuya dilucidación facilita la comprensión de un principio fundamental de su metafísica, y también, de manera derivada, la de la forma propia de prácticamente toda la gran filosofía sistemática del XVII. ${ }^{53}$ Aunque en la inmensa mayoría de los casos esta forma se forje en encarnizada polémica con la metafísica del francés. Cada vez que éste trata de Dios como del creador de las verdades eternas, lo compara con un monarca, o con un legislador. El modelo del que se sirve para pensar -y explicarla naturaleza de la acción de Dios es el de la soberanía, el del poder soberano de los monarcas.

Sabemos que la potencia, o, mejor, el poder de esa suerte de monarca que es Dios carece de límites, es absoluto; sabemos que nada, puesto que es infinito, puede limitarlo. El principio de contradicción, por ejemplo, no podría establecer límite alguno a sus posibilidades creadoras; es el poder de Dios, por el contrario, lo que precede y determina lo posible y lo contradictorio. Además, y puesto que la libertad indiferente de Dios es igualmente absoluta, no puede hallarse limitada a una cierta y determinada capacidad de elegir entre un cierto y determinado conjunto de posibles aquellos que libremente quiera actualizar; el Dios de Descartes no es el Dios de Leibniz, ni el de Malebranche; tampoco, aunque por razones radicalmente diferentes, el de Spinoza. ¿A qué imagen recurrir para explicar una concepción de la potencia que se quiere original? Aquí no cabe ni un instante de vacilación: a la imagen de la monarquía absoluta, pues Descartes considera que semejante metáfora pone inmediata, intuitivamente de manifiesto la absoluta trascendencia e ilimitación del poder y la libertad del Dios-autor que está conceptualizando. Aunque -io porque?- lo esté haciendo, por así decir, como negativamente.

\footnotetext{
53 Bien sea porque siga la senda abierta al pensamiento por esta metáfora -es el caso de Hobbes, Gracián, Leibniz, Malebranche o Saavedra Fajardo, por poner unos pocos ejemplos-, o porque la abandone radicalmente -es el caso, único hasta donde nosotros sabemos, del sistema de Spinoza.
} 
Absoluta trascendencia, ilimitación y libertad, decíamos. El 29 de julio de 1648 se explicará, en carta latina remitida a Arnauld, en los siguientes términos:

[...] esta dificultad [conocer la imposibilidad de que se dé el vacío, que la nada no puede tener propiedad alguna] proviene también de que recurrimos a la potencia divina; y como sabemos que es infinita, no prestamos atención al hecho de que le atribuimos un efecto que encierra una contradicción en su concepción, es decir, que no puede ser concebido por nosotros. Por lo que a mí respecta, me parece que jamás debe decirse de cosa alguna que es imposible para Dios; pues al depender todo lo que es verdadero y bueno de su omnipotencia, no me atrevo a decir siquiera que Dios no puede hacer una montaña sin valle, o que uno y dos no sean tres; sino que digo, solamente, que me ha dado un ingenio de naturaleza tal que no podría yo concebir una montaña sin valle, ni que la suma de uno y dos no sean tres, etc. Y digo solamente que tales cosas implican contradicción en mi concepción ${ }^{54}$

La potencia de Dios, así pues, es pensada según el modelo de la soberanía, lo cual sólo es posible si la potencia de Dios es pensada como se hace en este sistema: como un poder, como algo del todo trascendente a aquello sobre lo que se ejerce, como indistinguible de una voluntad absoluta e indiferente, ajeno por su propia esencia a todo tipo de necesidad. En definitiva, como algo que, por una parte, funda la necesidad desde cierto tipo de arbitrariedad, y que, por otra, aunque por ello, es esencialmente ininteligible. Sobre todo esencialmente ininteligible.

Ahora bien, Dios, leemos en este texto, ha dado al hombre «un ingenio de naturaleza tal que no podría yo concebir una montaña sin valle, ni que la suma de uno y dos no sean tres». ¿Significa esto que resulta imposible saber si la estructura racional de la conciencia, del cogito, carece de un fundamento sólido y que, en consecuencia, es imposible saber de un modo seguro si el conocimiento del hombre está condenado, o no, a ser tan sólo una pura ficción, una pura fantasmagoría, un puro sueño? La respuesta a esta pregunta debe ser rotundamente negativa. Vayamos cerrando ya nuestros análisis. La última cita que hemos dado del texto del 15 de abril de 1630 continúa de la siguiente manera:

Ahora bien, no hay ninguna [ley de la naturaleza] en particular que nosotros no podamos comprender si nuestro ingenio se vuelca a considerarla, y todas ellas son mentibus nostris ingenitae - del mismo modo que un rey imprimiría sus leyes en el corazón de todos sus súbditos si también tuviese el poder para hacerlo-. Al contrario, nosotros no podemos comprender la grandeza de Dios, aunque la conozcamos. Pero esto mismo, que la juzguemos incomprensible, nos la hace estimar aún más -al igual que un rey posee mayor majestad cuanto menos familiarmente es conocido por sus súbditos, con tal, no obstante, de que no piensen por ello carecer de rey, y de que le conozcan lo bas-

54 AT, V, 223-224. 
tante como para no dudar de ello-. Se os dirá que si Dios hubiese establecido estas verdades, las podría cambiar como un rey que hace sus leyes. A lo cual es preciso responder que sí, si es que su voluntad puede cambiar. -Mas yo las comprendo como eternas e inmutables. -Y yo, yo juzgo lo mismo de Dios. -Pero su voluntad es libre. -Sí, pero su potencia es incomprensible; y, generalmente, podemos asegurar que Dios puede hacer todo lo que nosotros podemos comprender, pero no que no puede hacer lo que nosotros no podemos comprender. Pues sería una temeridad pensar que nuestra imaginación posee tanta extensión como su potencia 55

La recurrente metáfora de la monarquía funciona como un modelo, como una imagen; sirve para pensar la potencia mediante una suerte de analogía. Lo cual significa que deben establecerse algunas diferencias totalmente irrebasables entre los términos de la comparación, entre la soberanía propia de Dios sobre todo lo que es, sobre la naturaleza toda, y la de los reyes -meras criaturas finitas-sobre sus reinos. Precisamente en la elucidación de estas diferencias se forjará la fundamentación metafísica de la verdad. Primera diferencia fundamental: las leyes que Dios instaura han sido impresas «en nuestros corazones», como haría un rey «si también tuviese el poder de hacerlo».

Debe quedar claro antes que nada que la verdad, que la necesidad racional, a pesar de ser una criatura como lo son todas las cosas contingentes, es algo que está bien fundado al menos en el sentido de que, aun cuando Dios no haya querido necesariamente crear ciertas verdades, de ello no se sigue que no haya querido que ciertas verdades creadas sean necesarias. La afirmación según la cual las verdades eternas son creación divina, no tiene por qué entrañar la afirmación de la relatividad de nuestro saber. ${ }^{56}$ Descartes se expresará así en carta al padre Mesland del 2 de mayo de 1644:

[...] aunque Dios haya querido que ciertas verdades fueran necesarias, esto no es lo mismo que decir que las haya querido necesariamente, pues es totalmente distinto querer que fueran necesarias, que quererlo necesariamente, o ser necesitado a quererlo. 57

Ello parece evidente en la concepción cartesiana. Invirtamos los términos del texto manteniendo su sentido: Dios no ha querido «necesariamente» ciertas verdades, no ha podido ser «necesitado» a querer o a crear determinadas verdades en detrimento de otras, pero sí ha podido querer que ciertas verdades, que quiere o crea libre, indiferentemente, sean creadas como «necesarias». Dios crea arbitrariamente las verdades, habría podido crear otras, pero una vez que ha creado las que efecti-

\footnotetext{
55 AT, I, 145-146.

56 Cf. É. Boutroux, Des vérités éternelles chez Descartes, op. cit., p. 46, y 76 ss., y G. Rodis-Lewis, Idées et vérités éternelles chez Descartes et ses successeurs, op. cit., pp. 7 y 127.

57 AT, IV, 118-119. Cf. J.-M. Beyssade, La philosophie première de Descartes, op. cit., p. 110 y ss.
} 
vamente ha creado, éstas no pueden cambiar: las verdades son efectivamente eternas e inmutables, aunque lo sean no porque su necesidad intrínseca se imponga incluso a la voluntad de Dios, sino más bien porque la voluntad de Dios deberá mostrarse como lo verdaderamente eterno e inmutable. La arbitrariedad de Dios -he aquí el sentido del desplazamiento que impone la analogía con la que se construye esta metafórica- no debe confundirse con la arbitrariedad humana, con la voluntad caprichosa y cambiante de los monarcas absolutos. ${ }^{58}$ La arbitrariedad de la omnipotencia divina es siempre una arbitrariedad de derecho, nunca de hecho. Este Diosautor-soberano-libre en sentido absoluto habría podido decretar otra cosa, habría podido instituir otra racionalidad, otras verdades eternas incluso contradictorias con las que efectivamente ha instituido. Pero desde el momento en que ha decretado algo, esto no puede ya cambiar. La instauración de la racionalidad, de la verdad -instauración que la convierte en algo de derecho contingente, al menos desde la perspectiva de Dios-, establece inamoviblemente, por tanto, la necesidad racional y natural -al menos desde el punto de vista del hombre-. Y ello porque el poder que la instaura es pensado como omnipotencia, y como omnipotencia en sí misma ininteligible. Digámoslo con Jean-Luc Marion: la necesidad, puesto que resulta de la especial arbitrariedad de Dios, puesto que ha sido creada -y lo ha sido de una vez por todas- recibe un fundamento incomprensible, y por ello mismo inquebrantable. $59 \mathrm{El}$ hecho de que haya sido creada, precisamente, por un Dios cuya voluntad es definitiva y, por ello, definitoria, es lo que le otorga un fundamento, y un fundamento absoluto. Todo obliga a pensar que Dios mantiene, creándola, una necesidad natural y racional que se revela al entendimiento finito del hombre como absoluta; entendimiento finito, a su vez, que ni siquiera puede representarse, debido a su misma finitud, la posibilidad de una verdad contradictoria respecto de la efectivamente instaurada - que una montaña carezca de valle, que uno más dos no sean tres-. Necesidad racional y natural, en fin, que desde el momento en que Dios es pensado como causa omnipotente de absolutamente todo lo que es, no puede dejar de ser considerada «como efecto de una causa libre, es decir, de una voluntad indiferente que no está sometida a ella» ${ }^{60}$. La soberanía divina carece, ciertamente, de las restricciones a que se ve sometida cualquier soberanía finita, humana, por el mero hecho de ser finita. Esto es, imperfecta también en el sentido de inacabada, de cambiante.

\footnotetext{
58 Aunque formalmente sean idénticas, pues la voluntad humana y la divina son formalmente idénticas. Cf. AT, IX, 45-46 (cuarta Meditación), o la carta a Mersenne del 25 de diciembre de 1639 (AT, II, $628)$.

59 Cf. J.-L. Marion, Sur la théologie blanche de Descartes, op. cit., p. 306. Un sentido más «antropomórfico» de la arbitrariedad divina es defendido por B. Rousset, Spinoza, lecteur des Objections faites aux Méditations de Descartes et de ses Réponses, op. cit., passim.

60 J.-M. Beyssade, Études sur Descartes, op. cit., p. 77.
} 
Pero lo que en este respecto se revela como esencial es la matización del propio Descartes: Dios actúa del mismo modo que «un rey que imprimiría sus leyes en el corazón de todos sus súbditos», cosa para la cual un monarca humano carece de poder. La afirmación de que Dios sí dispone de ese poder - la afirmación de que Dios es ese poder mismo- significa muy precisamente la aserción de que las verdades eternas son «innatas» en nuestra conciencia, o sea, que son inherentes tanto al hombre como a la naturaleza -pues el estatuto de la verdad no difiere, en principio, del propio del resto de criaturas-. La racionalidad, por tanto, aunque instituida desde su exterior en virtud de la ininteligible omnipotencia y la soberana libertad de indiferencia de Dios, está bien fundada ${ }^{61}$ : si la creación divina de las verdades eternas significa que éstas son inherentes a la naturaleza - una vez creada-y que ninguna diferencia puede establecerse entre ellas y el fuero interno de los hombres -pues se hallan «impresas en su corazón»-, ninguna exterioridad puede darse entre dichas leyes y dicho fuero interno de los hombres: son innatas. Es decir, las leyes impresas en nosotros coinciden necesariamente con las leyes de la naturaleza; son nuestra naturaleza misma. Y por ello no podemos concebir «una montaña sin valle» ni que uno y dos no sean tres, de la misma manera que no pueden existir efectivamente, una vez creadas, una montaña sin valle, ni una verdad que contradiga que uno más dos suman tres. Que el acto de la creación sea único y total, determina, pues, la institución de una única estructura racional en la naturaleza: en el hombre -la de su fuero interno o conciencia- y en el mundo físico - la de las verdades eternas, la de las leyes de la física, la matemática y la geometría.

El rendimiento de esta teoría de la libre creación de la verdad es, por tanto, en este último sentido que venimos analizando, doble. Por una parte, salvaguarda, refuerza, hace definitiva la transcendencia, omnipotencia e ininteligibilidad de Dios, del fundamento último de todo lo que es. Y por otra, simultánea y consecuentemente, abre al hombre, por la ciencia, por la racionalidad, a una comprensión fundada inapelablemente -verdadera- de la naturaleza, y también le abre a su dominio ${ }^{62}$. Dios, ciertamente, se halla situado más allá de la verdad, y del bien. Pero sólo Dios. El resto de criaturas está sometido necesariamente a la norma de verdad y bien. Y de entre tales criaturas sólo una, el hombre, es capaz de comprender la estructura de la creación y, comprendiéndola, dominarla. Tales son, en definitiva las

${ }^{61}$ Cf. H. Gouhier, La pensée métaphysique de Descartes, op. cit., pp. 245: «Les commentaires que Descartes a données de cette doctrine ont pour principal objet de prévenir toute interprétation atténuant le sens du mot: création. Ils assimilent rigoureusement la création des vérités éternelles à celle du monde, sans reculer devant la conséquence qui met à l'origine de leur nécessité la souveraine indifférence de la liberté divine»; y p. 246: «Immuables parce qu'éternelles ou éternelles parce qu'immuables, la valeur de la science reste intacte. C'est sans doute pourquoi Descartes tient à exposer en tête de sa physique son opinion sur l'origine des vérités mathématiques. Si leur création les rend contingentes par rapport à Dieu, elle n'affaiblit en rien leur nécessité pour l'entendemet humain...»

62 Cf. G. Rodis-Lewis, Idées et vérités éternelles chez Descartes et ses successeurs, op. cit., p. 128. 
bases de las que Descartes parte y el horizonte intelectual que fundan y en el que sitúan a nuestro autor; es decir, el punto de partida que determina la forma y los contenidos del especial itinerario que recorre en su reflexión a partir del año 30 y que va a fijar las coordenadas de su posición propia en la refriega filosófica del siglo...

$* * *$

En efecto, recordemos rápidamente que el comienzo de dicho itinerario ha consistido en el planteamiento de una posibilidad - «no sabemos si [Dios] ha querido hacernos de tal manera que estemos siempre engañados»- que se halla, y en esto coinciden prácticamente todos los comentadores, ${ }^{63}$ esencialmente vinculada a la idea según la cual Dios crea las verdades eternas. Pues, ciertamente, sólo es posible ponerlo todo en duda, incluso aquellas verdades cuyo cuestionamiento se presenta como contradictorio, si se concibe que éstas no se imponen en sí mismas, ni por sí mismas, a una razón que sea increada: la razón de Dios. La hipótesis de un Deus deceptor sólo es planteable si se considera a Dios fundamentalmente como un Deus creator que crea todo lo que es y que lo crea a idéntico título. Dicho de otra mane$\mathrm{ra}$, si se dispone de la idea de un Dios absolutamente creador cuyo entendimiento transcienda absolutamente al nuestro. O sea, de una idea de Dios que, abandonando cierta tradición especialmente pregnante, no dé por supuesto que Dios es la Verdad, ni que las verdades que están a nuestro alcance se hallan inscritas en la esencia de la única inteligencia que es eterna ${ }^{64}$. La «ficción metodológica» 65 de un Deus deceptor constituye así la condición que instaura el primer jalón del largo proceso que conduce a Descartes a demostrar, o a pensar haber demostrado, que la racionalidad es inatacable. Es decir, constituye la «primera parte» del recorrido que debe atravesar la reflexión metafísica, pues dicha demostración es lo que daba a aquél un sentido.

${ }^{6}$ Cf. G. Rodis-Lewis, Idées et vérités éternelles chez Descartes et ses successeurs, op. cit., pp. 119124; H. Gouhier, La pensée religieuse de Descartes, op. cit., pp. 76 y ss.; id., La pensée métaphysique de Descartes, op. cit., pp. 67-71, 113-121 y 257-264. Contra, cf. M. Gueroult, Descartes selon l'ordre des raisons, I. L'âme et Dieu, op.cit., pp. 43-45.

${ }^{64} \mathrm{Cf}$. H. Gouhier, La pensée métaphysique de Descartes, op. cit., pp. 257-260: «Ainsi, jamais le théologien augustinienne ou thomiste n'eut l'occasion d'invoquer la véracité de Dieu précisément parce que la possibilité d'invoquer la Vérité qui est Dieu le dispensait du problème dont la solution appelle la véracité. Inversement, le philosophe cartésien invoque la véracité précisément parce que l'impossibilité d'invoquer la Vérité qui est Dieu le conduit au problème dont la solution appelle la véracité. Ce qui signifie: l'hypothèse du Dieu trompeur n'est possible comme supposition que par référence à un Dieu créateur des réalités éternelles» (p. 258).

65 Cf. H. Gouhier, La pensée métaphysique de Descartes, op. cit., pp. 113-121; y L.J. Beck, The Metaphysics of Descartes. A Study of the Meditations, Oxford, Oxford University Press, 1965, pp. 68-76. 
Volvamos ya al punto del que hemos partido nosotros. Parece indudable que la filosofía debe disponer casi desde su comienzo de un cierto conocimiento o de una determinada idea de Dios. Pero de un conocimiento o idea que se ajusta perfectamente a la medida de lo que el momento inicial de la reflexión, la verdad del cogito, exige. Si se hace necesaria una cierta consideración de la naturaleza de Dios, o de alguno de sus atributos -es decir, del primer principio o primera causa del ser-, dicha consideración debe plegarse al itinerario que diseña el principio de la filosofía -esto es, el primer principio o primera causa del conocer-.66 Y el orden de las razones del sistema cartesiano exige absolutamente, una vez encontrado su principio, demostrar que Dios, aunque podría hacerlo - pues la veracidad divina no cuestiona la omnipotencia de Dios: Dios podría engañarnos, pero carece de la voluntad de hacerlo-, no utiliza su omnipotencia de manera arbitraria en un sentido humano. Dios, su perfección, debe garantizar que tales ideas son verdaderas.

Así pues, nuestra conclusión será ésta: el punto de partida en el orden del conocimiento no es explícitamente la idea de Dios, pero el hallazgo de la inatacable verdad de la existencia del cogito, primer principio de la «verdadera filosofía» tal como la concibe Descartes, es legible sólo sobre el trasfondo de una cierta consideración de la naturaleza divina y de su trascendencia. El ordo cognoscendi exige tomar como principio la existencia o el ser del cogito; principio que no coincide con el principio o con la causa de «todo lo que es, o puede ser». La «verdadera filosofía», por tanto, sólo parece posible a partir de una suerte de desajuste estructural entre ordo essendi y ordo cognoscendi. Pero este desajuste parece -y no lo parece menos- tan sólo heurístico, expositivo. Por todo ello, tal vez haya que buscar el fundamento de la novedad de la reflexión cartesiana - esto es, su verdadera novedad, su verdadero momento o principio «revolucionario»- en otro sitio, en otro principio o en otro concepto. Y tal vez este concepto sea aquel en torno a cuya reflexión se ha configurado efectiva, realmente la filosofía más sistemática de la inmediata posteridad de Descartes. Las revoluciones, aunque sean sólo teóricas, lo son únicamente si se muestran capaces de dar una forma estable a un porvenir nuevo, y el sistema del autor de las Meditaciones metafísicas, desde luego, ha dado su forma propia al nuevo espacio teórico de la filosofía de la primera modernidad.

Ahora bien, esta forma no ha impuesto necesariamente la aceptación de aquel desajuste entre ordo essendi y ordo cognoscendi, ni tampoco la necesidad de reorganizar el orden de las partes que tradicionalmente se han atribuido a la metafísica. Por ello, nuestra tesis será que aquella novedad, aquella auténtica revolución teórica realizada por la obra de Descartes, ha de ser buscada más bien en el concepto

\footnotetext{
$66 \mathrm{Cf}$. AT, IX-2, 37: «[...] el primero de sus atributos que parece que debe ser aquí considerado, consiste en que [Dios] es muy veraz y la fuente de toda luz, de suerte que no es posible que nos engañe, es decir, que sea la causa de los errores a que estamos sujetos y que experimentamos en nosotros mismos». Véase también la Meditación cuarta (AT, IX, 43-44).
} 
donde la reflexión inmediatamente posterior a la suya -incluso contemporáneapercibe la verdadera fuerza de la posición filosófica del francés. De este modo, si puede afirmarse legítimamente que la fuerza con que renueva el saber filosófico de su tiempo no se encuentra realmente en la reorganización que propone del orden que debe seguir la «verdadera filosofía», tal vez sí quepa reconocer dicha fuerza en la manera como ha tematizado un concepto sobre el que efectivamente se detendrán todos cuantos pretendan decir algo significativo en filosofía en el siglo XVII. Y lo harán, en primer lugar, y más allá de toda duda razonable. para saldar sus cuentas con la posición propia de Descartes respecto de ese concepto. Es esto lo que nos indica con alguna precisión dónde se ha percibido en su propia época el ímpetu renovador de su metafísica. La noción a la que nos referimos es aquella que hemos querido analizar con este artículo y que él mismo no se ha cansado nunca de reconceptualizar vinculándola a la problemática epistemológica de la que parte. Nos referimos, como es obvio, al concepto de potencia, pues ciertamente es la reflexión sobre este concepto -y sobre los conceptos con él conjugados de racionalidad y de trascendencia-, pero no la redistribución que propuesta a propósito del orden de las partes de la metafísica -redistribución que en muchos autores es obviada, cuando no directamente negada, sin que por ello hayan dejado de considerar explícitamente, ellos mismos, que la función esencial de la metafísica cartesiana ha sido la de abrir una nueva época para el pensamiento-, lo que determinará las posiciones de la filosofía más sistemática del siglo, de Leibniz a Malebranche, de Hobbes a Spinoza, de Gracián a Pascal. Y también lo que determinará las diferentes maneras de abordar la tópica que nuestro autor lega a su tiempo: la cuestión del método, del cogito, de la verdad, de la existencia de Dios, del innatismo de ciertas ideas, etc. Tópica que también él ha recorrido y organizado, como hemos tratado de poner de manifiesto en estas páginas, desde su particular y original concepción de la potencia divina. Esto será, en fin, lo que otorgue casi definitivamente una fisonomía propia al siglo. Y lo será, quizás, porque es lo que ha dado su sabor filosófico propio al sistema cartesiano. Si esta hipótesis tuviera alguna solidez, dispondríamos de una perspectiva nueva desde la que pensar con energías renovadas el verdadero carácter inaugural de la metafísica de Descartes, y también la forma específica de un período tan denso conceptualmente como el siglo XVII. Es decir, podríamos intervenir desde una perspectiva nueva en el fundamental debate sobre la especificidad filosófica de unos tiempos, los de la primera modernidad, que, para bien o para mal, de una manera o de otra, han determinado el ya desgastado tejido de los nuestros.

Pedro Lomba Falcón

Departamento de Historia de la Filosofía

Facultad de Filosofía

Universidad Complutense de Madrid

pedro.lomba@filos.ucm.es 